\title{
Genome-Wide Analysis of Small Secreted Cysteine-Rich Proteins Identifies Candidate Effector Proteins Potentially Involved in Fusarium graminearum-Wheat Interactions
}

\author{
Shunwen Lu and Michael C. Edwards
}

U.S. Department of Agriculture-Agricultural Research Services, Cereal Crops Research Unit, Fargo, ND 58102-2765.

Accepted for publication 28 October 2015.

\begin{abstract}
Lu, S., and Edwards, M. C. 2016. Genome-wide analysis of small secreted cysteine-rich proteins identifies candidate effector proteins potentially involved in Fusarium graminearum-wheat interactions. Phytopathology 106:166-176.

Pathogen-derived, small secreted cysteine-rich proteins (SSCPs) are known to be a common source of fungal effectors that trigger resistance or susceptibility in specific host plants. This group of proteins has not been well studied in Fusarium graminearum, the primary cause of Fusarium head blight (FHB), a devastating disease of wheat. We report here a comprehensive analysis of SSCPs encoded in the genome of this fungus and selection of candidate effector proteins through proteomics and sequence/transcriptional analyses. A total of 190 SSCPs were identified in the genome of $F$. graminearum (isolate PH-1) based on the presence

liquid chromatography-tandem mass spectrometry (nanoLC-MS/MS) analysis of a minimal medium-based in vitro secretome. Sequence analysis suggested that 17 SSCPs harbor conserved functional domains, including two homologous to Ecp2, a known effector produced by the tomato pathogen Cladosporium fulvum. Transcriptional analysis revealed that at least 34 SSCPs (including 23 detected in the in vitro secretome) are expressed in infected wheat heads; about half are up-regulated with expression patterns correlating with the development of FHB. This work provides a solid candidate list for SSCP-derived effectors that may play roles in mediating $F$. graminearum-wheat interactions. The in vitro secretome-based method presented here also may be applicable for identifying candidate effectors in other ascomycete pathogens of crop plants.
\end{abstract} of N-terminal signal peptide sequences, size ( $\leq 200$ amino acids), and cysteine content $(\geq 2 \%)$ of the mature proteins. Twenty-five (approximately $13 \%$ ) SSCPs were confirmed to be true extracellular proteins by nanoscale
Additional keywords: fungal pathogenesis, gene-for-gene interactions, host resistance, virulence factors, wheat scab disease.
During colonization of host plants, many fungal pathogens produce and secrete diverse small molecules of secondary metabolites or proteins, some of which are known to act as pathogenicity or virulence determinants that manipulate the interactions between the pathogen and specific host plants, thus being commonly referred as "effectors" (Rep 2005; Stergiopoulos and de Wit 2009; Templeton et al. 1994).

Fungal proteinaceous effectors have been identified in a number of ascomycetes, including biotrophic, hemibiotrophic, and necrotrophic pathogens. Biotrophic and hemibiotrophic effectors are best known as avirulence (Avr) proteins. Examples are Avr9 and Ecp2 produced by the tomato leaf mold fungus Cladosporium fulvum and the SIX proteins produced by the vascular wilt fungus Fusarium oxysporum f. sp. lycopersici (reviewed by Stergiopoulos and de Wit 2009). Necrotrophic effectors are often known as host-selective toxins. Examples are ToxA and ToxB produced by the tan spot fungus Pyrenophora tritici-repentis (reviewed by Ciuffetti et al. 2010), and SnTox 1 and SnTox3 produced by the leaf/glume blotch fungus Parastagonospora nodorum (Friesen et al. 2007; Oliver et al. 2012). Most fungal effector proteins identified so far are relatively small in size (usually $<200$ amino acids) and contain a high percentage (e.g., 2 to $20 \%$ ) of cysteine residues. Thus, it has been recognized

Corresponding author: S. Lu; E-mail address: Shunwen.Lu@ars.usda.gov

*The $\boldsymbol{e}$-Xtra logo stands for "electronic extra" and indicates that two supplementary tables are published online.

http://dx.doi.org/10.1094/PHYTO-09-15-0215-R

This article is in the public domain and not copyrightable. It may be freely reprinted with customary crediting of the source. The American Phytopathological Society, 2016. that small secreted cysteine-rich proteins (SSCPs) constitute a common source of fungal effectors.

$F$. graminearum is the major cause of Fusarium head blight (FHB), a devastating disease of wheat crops worldwide. In addition to causing severe yield losses, the fungus also poses a health risk to human and animals because it produces a number of mycotoxins (mainly trichothecenes) that may contaminate food and feed products (reviewed by Goswami and Kistler 2004; Xu and Nicholson 2009). The fungus is considered a "hemibiotrophic" pathogen since its pathogenic life cycle starts with a "biotrophic" phase, i.e., growing subcuticularly and intercellularly for a period of time before necrotizing host cells (Brown et al. 2010; Walter et al. 2010). Breeding for resistance has been the major means to control FHB. Quantitative trait loci-mediated resistance has been reported, but no gene-for-gene interactions have been identified in the F. graminearum-wheat pathosystem (reviewed by Buerstmayr et al. 2009). Several pathogenicity/virulence factors have been characterized in previous studies (Hou et al. 2002; Jonkers et al. 2012; Lu et al. 2003; Proctor et al. 1995; Seong et al. 2005; Urban et al. 2015; Voigt et al. 2005), but no SSCP-derived effectors have been reported for this fungus.

The genome of $F$. graminearum (isolate $\mathrm{PH}-1$ ) was completely sequenced about 10 years ago (Cuomo et al. 2007). The most recent annotation in the assembly 3 sequence released by the Broad Institute (http://www.broadinstitute.org) includes 13,321 proteins. Several in silica studies predicted over one thousand secreted proteins based on the presence of $\mathrm{N}$-terminal signal peptide (SP) sequences, including over 300 small cysteine-rich proteins (Brown et al. 2012; Krijger et al. 2014; Sperschneider et al. 2015) that were identified using different criteria and reported in statistical numbers only without detailed sequence or transcriptional analysis specifically 
to address potential association with FHB. Not all secreted proteins identified in silica are necessarily "true" extracellular proteins, because some of SP-containing proteins may be translocated to certain intracellular organelles (e.g., endosomes) other than being finally exported outside eukaryotic cells (Lodish et al. 2000). An early large-scale proteomics study identified only 289 extracellular proteins from the same $\mathrm{PH}-1$ isolate, including some cysteine-rich proteins that were not specified by the authors (Paper et al. 2007). To date, no detailed functional analysis has been reported for any SSCPs encoded in the $F$. graminearum genome.

We report here a comprehensive analysis of 190 SSCPs encoded in the genome of $F$. graminearum and identification of 25 extracellular SSCPs through nanoscale liquid chromatography-tandem mass spectrometry (nanoLC-MS/MS) analysis. We demonstrate through transcriptional analysis that at least $34 F$. graminearum SSCPS (including 23 detected by nanoLC-MS/MS) are expressed in planta; about half are up-regulated with expression patterns correlating with the development of FHB on susceptible wheat. The data presented in this study represent an important step toward functional characterization of SSCP-derived effectors that may play important roles in mediating $F$. graminearum-wheat interactions.

\section{MATERIALS AND METHODS}

Fungal isolate and culture conditions. F. graminearum isolate PH-1 used in this study was provided (via R. Goswami) by C. Kistler of the USDA-ARS Cereal Disease Laboratory at St. Paul, $\mathrm{MN}$ and kept at $-80^{\circ} \mathrm{C}$ as glycerol stocks. For sporulation, the isolate was grown on agar plates containing complete medium with xylose (CMX) as a carbon source (Tzeng et al. 1992) and incubated in a Percival I-36BLL biological incubator (Percival Scientific, Inc., Perry, IA) at $22^{\circ} \mathrm{C}$ with continuous fluorescent lighting. For liquid cultures, fungal conidia were collected from CMX plates and inoculated into $50 \mathrm{ml}$ of minimal medium (MM) that contained glucose (10 g per liter) as a carbon source and no nitrogen sources (Leach et al. 1982). Basic salts and trace elements included in MM (per liter) were as follows: $\mathrm{CaNO}_{3} \cdot 4 \mathrm{H}_{2} \mathrm{O}, 1 \mathrm{~g} ; \mathrm{KH}_{2} \mathrm{PO}_{4}, 1 \mathrm{~g} ; \mathrm{MgSO}_{4}$. $7 \mathrm{H}_{2} \mathrm{O}, 0.25 \mathrm{~g} ; \mathrm{NaCl}, 0.15 \mathrm{~g} ; \mathrm{CuSO}_{4} \cdot 5 \mathrm{H}_{2} \mathrm{O}, 196.5 \mu \mathrm{g} ; \mathrm{FeCl}_{3} \cdot 6 \mathrm{H}_{2} \mathrm{O}$, $474.1 \mu \mathrm{g} ; \mathrm{H}_{3} \mathrm{BO}_{3}, 28.6 \mu \mathrm{g} ; \mathrm{KI}, 6.5 \mu \mathrm{g} ; \mathrm{MnSO}_{4} \cdot \mathrm{H}_{2} \mathrm{O}, 30.2 \mu \mathrm{g}$; $\left(\mathrm{NH}_{4}\right)_{6} \mathrm{Mo}_{7} \mathrm{O}_{24} \cdot 4 \mathrm{H}_{2} \mathrm{O}, 18.4 \mu \mathrm{g}$; and $\mathrm{ZnSO}_{4} \cdot \mathrm{H}_{2} \mathrm{O}, 2,745 \mu \mathrm{g}$. The inoculated liquid cultures were incubated at room temperature with slow shaking for 2 days and then left on the bench for an additional 6 or 12 days before collecting mycelia and culture filtrates as described below.

Preparation of culture filtrate proteins for mass spectrometry analysis. Fungal culture supernatants were collected from MM liquid cultures 8 and 14 days postinoculation by passage through four layers of cheesecloth followed by centrifugation at 4,000 rpm for $5 \mathrm{~min}$. The collected supernatants were filtered through a $0.45 \mu \mathrm{m}$ syringe filter (Fisher Scientific, Waltham, MA) and the filtrate proteins were concentrated $\sim 20$ times using a centrifugal filter unit (EMD Millipore, Billerica, MA) following the manufacturer's instructions. The concentrated proteins were then desalted through a Bio-Gel P-6DG column (Bio-Rad, Hercules, CA). The resultant protein samples were checked for possible microbial contaminants using bioassays in which the sample solutions were spread on CMX (for fungi) and LB broth (for bacteria) agar plates and incubated for appropriate times. Thirty microliters of desalted culture filtrate proteins was subjected to sodium dodecyl sulfatepolyacrylamide gel electrophoresis (SDS-PAGE) analysis on a $15 \%$ polyacrylamide gel following standard procedures (Green and Sambrook 2012). The concentration of the total proteins was estimated by comparison with a series of dilutions of bovine serum albumin (BSA) (New England Biolabs, Ipswich, MA) included in the same SDS-PAGE gel. About $300 \mu \mathrm{l}$ of the concentrated culture filtrate proteins was subjected to shotgun protein ID analysis through nanoscale liquid chromatography-tandem mass spectrometry (nanoLC-MS/MS) at the Cornell University Biotechnology Resource
Center (www.biotech.cornell.edu/biotechnology-resource-center-brc) that was performed as a standard technical service. SSCPs detected by nanoLC-MS/MS are listed in Table 1 and also can be found in the complete list of SSCPs identified in the $F$. graminearum genome (Supplementary Table S1).

Nucleic acid preparations. For mRNA extractions, fungal mycelia (collected from liquid MM cultures by centrifugation) or fragmented tissues of wheat heads were transferred into 2-ml Lysing Matrix D tubes containing 1.4-mm ceramic spheres (QBiogene, Morgan Irvine, CA) and frozen in liquid nitrogen, followed by homogenization using a Mini-Bead-beater-16 Cell Disrupter (BioSpec Products, Bartlesville, OK). mRNA was extracted from the homogenized tissues using the Dynabeads mRNA Direct Kit (Invitrogen, CA) following the manufacturer's instructions and finally eluted in Tris-HCl buffer ( $\mathrm{pH}$ 8.0). cDNA synthesis was done using the Superscript III first strand synthesis system (Invitrogen, Carlsbad, CA).

Plant inoculations. Plants of susceptible common wheat (Triticum aestivum) variety 'Grandin' were grown in 6-inch pots (10 to 16 plants/per pot) containing SB100 professional growing mix (Sungrow Horticulture, Bellevue, WA) in a growth chamber at an average temperature of $21^{\circ} \mathrm{C}$ with a 16 -h photoperiod and allowed to grow to anthesis stage (about 6 weeks). For inoculation, macroconidia were collected from 20- to 25 -day-old fungal cultures grown on CMX plates and suspended in $0.05 \%$ Tween 80 solutions with the concentrations adjusted to $1 \times 10^{7} / \mathrm{ml}$. Plants were inoculated by spraying the conidial suspensions using a sprayer replacement power unit (Preval, Coal City, IL). Control plants were sprayed with water only. Inoculated plants were kept in a mist chamber for $72 \mathrm{~h}$ and then returned to the growth chamber. Symptoms were recorded at seven different time points $(4,12,24,48$, and $72 \mathrm{~h}$ and 8 and 14 days postinoculation) during FHB development.

Gene expression profiling. Reverse-transcriptase-polymerase chain reaction (RT-PCR) was performed using mRNA samples isolated from wheat head tissues collected at the seven time points mentioned above. DNA oligo primers (Supplementary Table S2) were designed based on mRNA sequences of targeted SSCPs that were retrieved from the NCBI databases (http://www.ncbi.nlm.nih. gov/). Concentrations of different cDNA samples were adjusted to be comparable by serial dilutions against the expression level of the F. graminearum actin gene (GenBank accession XM_011328784), which was used as an internal control. mRNA samples isolated from uninoculated plants were included as "negative" controls to check for possible cross-amplification of host plant-derived mRNA transcripts. mRNA samples isolated from fungal cultures used for the in vitro secretome were also included as controls. PCR was performed in a 25- $\mu$ l volume of $1 \times$ GoTaq Green Master Mix (Promega, Madison, WI) that contained $1 \mu \mathrm{l}$ of cDNA and $0.5 \mu \mathrm{M}$ of each primer. PCR was started with an initial preheat for $5 \mathrm{~min}$ at $95^{\circ} \mathrm{C}$, followed by 32 to 35 cycles of denaturation at $95^{\circ} \mathrm{C}$ for $15 \mathrm{~s}$, annealing at 55 or $59^{\circ} \mathrm{C}$ for $15 \mathrm{~s}$, and extension at $72^{\circ} \mathrm{C}$ for $1 \mathrm{~min}$, with a final extension at $72^{\circ} \mathrm{C}$ for $10 \mathrm{~min}$. PCR products were separated on a $1 \%$ agarose/ethidium bromide gel in TAE buffer. Targeted PCR products were purified using the QIAquick PCR Purification Kit (Qiagen, Valencia, CA) and sequenced at the Cornell University Biotechnology Resource Center to confirm the identity of the amplicons. All RT-PCR tests were repeated at least twice to verify the observed gene expression patterns.

Sequence analysis. Amino acid sequences of $F$. graminearum SSCPs and related proteins from other fungal species were retrieved from GenBank databases available online from the National Center for Biotechnology Information (http://www.ncbi.nlm.nih.gov/) and the Fungal Genome Initiative databases available online from the Broad Institute (http://www.broadinstitute.org). N-terminal signal peptide (SP) sequences and probable transmembrane domains were determined using the SignalP 4.1 and TMHMM 2.0 Servers, respectively, available online from the Center for Biological Sequence Analysis, Technical University of Denmark 
(http://www.cbs.dtu.dk). Molecular masses, isoelectric points $(\mathrm{pI})$, and the number/percentage of cysteine residues in the mature protein sequences were calculated using the ProtParam tool available online from the Swiss Institute of Bioinformatics (http://www.isb-sib.ch). Amino acid sequence alignments were generated using the MegAlign programs from Lasergene 8.1 software (DNASTAR Inc., Madison, WI). Potential functional domains were determined using the BLAST conserved domain (CD) search program (Marchler-Bauer et al. 2015) with a cut-off E value of 1e-05 considered as significant.

\section{RESULTS}

Identification of SSCPs encoded in the genome of F. graminearum. A total of 3,946 proteins annotated by the Broad Institute (http://www.broadinstitute.org) that consist of less than 250 aa (in full-length) were examined and about $10 \%$ were found to contain an N-terminal signal peptide (SP) sequence. Among these SP-containing proteins, 197 were selected as SSCPs based on the criteria that the predicted mature protein consists of $\leq 200$ aa and contains $\geq 2 \%$ cysteine residues. Seven proteins were later excluded because they contained apparent transmembrane domains. Thus, it was predicted that there are a total of 190 extracellular SSCPs encoded in the genome of $F$. graminearum.

The predicted mature proteins of the 190 SSCPs consisted of 35 to 200 aa with a majority $(140)>100$ aa (Fig. 1A). The smallest SSCPs were FGSG_08493 and FGSG_00847, both of which consisted of less than 50 aa, but which were still larger than the smallest known fungal effector, i.e., the 28 -aa Avr9 protein identified from the tomato pathogen C. fulvum (Van den Ackerveken et al. 1993). The percentage of cysteine was 2 to $13.8 \%$ with most (109) $<5 \%$ (Fig. 1A). Cysteine residues varied in number from 2 to 20 (only

TABLE 1. Characteristics of Fusarium graminearum small secreted cysteine-rich proteins (SSCPs) selected for transcriptional analysis

\begin{tabular}{|c|c|c|c|c|c|c|c|c|c|}
\hline Protein $^{a}$ & Size $^{b}$ & No. of Cys ${ }^{\mathrm{c}}$ & $\% \mathrm{Cys}^{\mathrm{c}}$ & $\mathrm{MW}^{\mathrm{d}}$ & $\mathrm{pI}^{\mathrm{e}}$ & Domain $^{f}$ & In vitrog & In plantah & Distribution $^{\mathrm{i}}$ \\
\hline FGSG_00060 & 118 & 10 & 8.5 & 12.4 & 4.5 & pfam09044 & (Yes) & $\mathrm{Yes}^{\wedge}$ & II \\
\hline$\overline{\text { FGSG_00061 }}$ & 107 & 8 & 7.5 & 11.1 & 4.5 & pfam09044 & (Yes) & $\mathrm{Yes}^{\wedge}$ & II \\
\hline$\overline{\text { FGSG_00062 }}$ & 117 & 10 & 8.5 & 12.1 & 4.2 & pfam09044 & (Yes) & $\mathrm{Yes}^{\wedge}$ & II \\
\hline$\overline{\text { FGSG_00129 }} *$ & 149 & 9 & 6 & 15.5 & 4.5 & $\mathrm{n} / \mathrm{a}$ & Yes & No & $\mathrm{n} / \mathrm{a}$ \\
\hline FGSG_00569 & 197 & 5 & 2.5 & 21.9 & 4.7 & pfam00188 & Yes & $\mathrm{Yes}^{\wedge}$ & $\mathrm{n} / \mathrm{a}$ \\
\hline$\overline{\text { FGSG_00588 }}$ & 143 & 10 & 7 & 14.1 & 4.7 & pfam05730 & Yes & Yes & II \\
\hline$\overline{\text { FGSG_01831 }}$ & 79 & 8 & 9.9 & 8.2 & 4.1 & pfam06766 & (Yes) & $\mathrm{Yes}^{\wedge}$ & II \\
\hline$\overline{\text { FGSG_02036* }}$ * & 155 & 7 & 4.5 & 16.7 & 4 & $\mathrm{n} / \mathrm{a}$ & Yes & Yes & I \\
\hline FGSG_02077* & 167 & 8 & 4.8 & 16.6 & 4.5 & pfam05730 & Yes & Yes & II \\
\hline$\overline{\text { FGSG_02181 }}$ & 138 & 8 & 5.8 & 13.8 & 4.2 & pfam05730 & No & No & I \\
\hline$\overline{\text { FGSG_03573 }}$ & 189 & 8 & 4.2 & 20.2 & 4.8 & pfam05730 & No & No & $\mathrm{n} / \mathrm{a}$ \\
\hline$\overline{\text { FGSG_03581* }} *$ & 178 & 4 & 2.3 & 19.4 & 6.2 & $\mathrm{n} / \mathrm{a}$ & Yes & Yes & II \\
\hline FGSG_03599 & 77 & 10 & 13 & 7.2 & 3.4 & pfam05730 & (Yes) & $\mathrm{Yes}^{\wedge}$ & I \\
\hline$\overline{\text { FGSG_03960 }}$ & 153 & 9 & 5.9 & 15.1 & 4.2 & pfam01185 & No & No & I \\
\hline$\overline{\text { FGSG_04074 }} *$ & 171 & 6 & 3.5 & 18.6 & 6.9 & $\mathrm{n} / \mathrm{a}$ & Yes & $\mathrm{Yes}^{\wedge}$ & III \\
\hline FGSG_04213* & 151 & 6 & 4 & 16.6 & 8.8 & $\mathrm{n} / \mathrm{a}$ & Yes & Yes & I \\
\hline FGSG_04239* & 186 & 14 & 7.5 & 19.5 & 8 & $\mathrm{n} / \mathrm{a}$ & Yes & Yes & III \\
\hline FGSG_04661* & 146 & 4 & 2.7 & 16.1 & 6.3 & $\mathrm{n} / \mathrm{a}$ & Yes & $\mathrm{Yes}^{\wedge}$ & I \\
\hline FGSG_04805* & 103 & 6 & 5.8 & 11.8 & 8.8 & $\mathrm{n} / \mathrm{a}$ & Yes & $\mathrm{Yes}^{\wedge}$ & I \\
\hline FGSG_05341 & 173 & 5 & 2.9 & 18.5 & 4.8 & pfam 14856 & Yes & $\mathrm{Yes}^{\wedge}$ & I \\
\hline$\overline{\text { FGSG_05714 }} *$ & 181 & 6 & 3.3 & 18.6 & 4.3 & $\mathrm{n} / \mathrm{a}$ & Yes & Yes & III \\
\hline FGSG_06597* & 195 & 10 & 5.1 & 19.5 & 4.1 & $\mathrm{n} / \mathrm{a}$ & Yes & No & I \\
\hline FGSG_06712* & 129 & 16 & 12.4 & 13.4 & 6.4 & $\mathrm{n} / \mathrm{a}$ & Yes & (Yes) & $\mathrm{I}$ \\
\hline FGSG_06993* & 184 & 4 & 2.2 & 20.3 & 6.9 & $\mathrm{n} / \mathrm{a}$ & Yes & Yes & III \\
\hline FGSG_08122* & 173 & 4 & 2.3 & 18.9 & 9.1 & $\mathrm{n} / \mathrm{a}$ & Yes & Yes & III \\
\hline FGSG_08164* & 124 & 9 & 7.3 & 14 & 7.6 & $\mathrm{n} / \mathrm{a}$ & Yes & (Yes) & $\mathrm{n} / \mathrm{a}$ \\
\hline FGSG_08210* & 134 & 10 & 7.5 & 13.4 & 4.6 & $\mathrm{n} / \mathrm{a}$ & (Yes) & $\mathrm{Yes}^{\wedge}$ & I \\
\hline FGSG_08554* & 192 & 8 & 4.3 & 18.4 & 4.5 & pfam05730 & Yes & Yes & $\mathrm{I}$ \\
\hline$\overline{\text { FGSG_09127 }} *$ & 97 & 8 & 8.2 & 11 & 6.9 & $\mathrm{n} / \mathrm{a}$ & Yes & (Yes) & III \\
\hline FGSG_09570* & 151 & 8 & 5.3 & 16.8 & 6.2 & $\mathrm{n} / \mathrm{a}$ & Yes & Yes & I \\
\hline FGSG_10206* & 146 & 8 & 5.5 & 15.6 & 8.7 & $\mathrm{n} / \mathrm{a}$ & (Yes) & $\mathrm{Yes}^{\wedge}$ & II \\
\hline FGSG_10212 & 121 & 4 & 3.3 & 12.7 & 8.9 & pfam07249 & Yes & Yes & III \\
\hline$\overline{\text { FGSG_10585* }}$ & 149 & 18 & 12.1 & 15.8 & 4.8 & $\mathrm{n} / \mathrm{a}$ & Yes & (Yes) & II \\
\hline FGSG_10603* & 137 & 8 & 5.8 & 14.7 & 9 & $\mathrm{n} / \mathrm{a}$ & Yes & (Yes) & II \\
\hline FGSG_11205* & 122 & 4 & 3.3 & 12.7 & 9.2 & pfam07249 & Yes & Yes & III \\
\hline$\overline{\text { FGSG_11318 }}$ & 135 & 4 & 2.9 & 14.2 & 6.3 & pfam 14856 & (Yes) & $\mathrm{Yes}^{\wedge}$ & III \\
\hline$\overline{\text { FGSG_12160 }}$ & 170 & 4 & 2.4 & 18.4 & 5.9 & pfam03443 & (Yes) & $\mathrm{Yes}^{\wedge}$ & III \\
\hline$\overline{\text { FGSG_13782 }} *$ & 76 & 6 & 7.8 & 8.8 & 6.3 & $\mathrm{n} / \mathrm{a}$ & Yes & Yes & $\mathrm{n} / \mathrm{a}$ \\
\hline FGSG_13952* & 85 & 10 & 11.8 & 9.1 & 5.7 & $\mathrm{n} / \mathrm{a}$ & (Yes) & $\mathrm{Yes}^{\wedge}$ & II \\
\hline
\end{tabular}

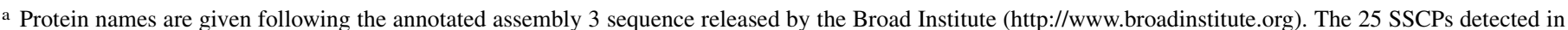
the in vitro secretome are indicated by asterisks. SSCPs containing conserved domains are underlined.

b Size indicates the number of amino acids in the predicted mature protein.

c No. of Cys and \% Cys represent the number and percentage of cysteine residues in the mature protein, respectively.

d MW indicates the predicted molecular masses of the mature proteins (in kDa).

e pI: Isoelectric point.

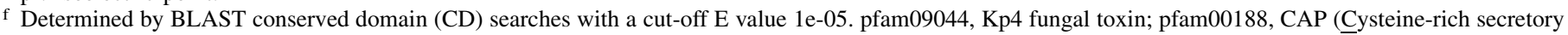
proteins, Antigen 5, and Pathogenesis-related 1 proteins) family; pfam05730, CFEM domain; pfam06766, hydrophobin_2; pfam01185, fungal hydrophobin: pfam $1485 \overline{6}$, Hce2 super family/pathogen necrosis-inducing factor; pfam07249, cerato-platanin; pfam03443, glycosyl hydrolase family_61. n/a, no significant similarity to any conserved domains.

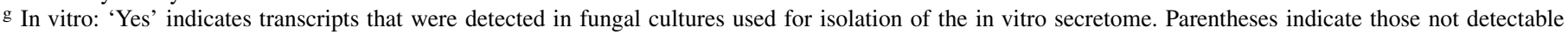
when the cDNA samples were diluted substantially, such as those used as one of the controls for in planta expression profiling shown in Figure 6 (c2, lanes 9).

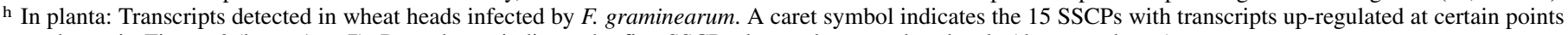
as shown in Figure 6 (lanes 1 to 7). Parentheses indicate the five SSCPs detected at very low levels (data not shown).

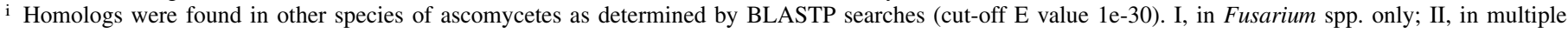
species in Sordariomycetes; III, in more than one class of ascomycetes. n/a, no homologs were detected in any other species. 
eight proteins contained $>10$ cysteines), with the majority appearing in even numbers, especially 4, 6, and 8 at higher frequencies $(23,20$, and $16 \%$, respectively) (Fig. 1B).

All 190 SSCPs were annotated as "hypothetical proteins" in the assembly 3 sequence released by the Broad Institute (http://www. broadinstitute.org), except for FGSG_09586 (phosphatidylinositol transfer protein) and FGSG_11190 (guanyl-specific ribonuclease F1 precursor). However, BLAST conserved domain (CD) searches suggested that 17 "hypothetical protein" SSCPs contain homologies to functional domains in the database (Marchler-Bauer et al. 2015), including some related to fungal plant pathogenesis (Table 1, Figure 1C). Sequence analysis revealed that these 17 SSCPs belong to eight different protein families (see below). Based on an E value cut-off of 1e-30 in BLAST searches, 27 (15\%) SSCPs appeared to be $F$. graminearum-specific because they all lack homologs in other fungal species, even those in the same genus. The other 163 SSCPs were found to have homologs in F. pseudograminearum (a sister species of $F$. graminearum) only (35), or in Fusarium spp. (57), or within Sordariomycetes (37), or in species of all major classes of ascomycetes (34) (Fig. 1C). When compared at amino acid level, most $F$. graminearum SSCPs lacked significant similarities to each other. Exceptions included those having conserved functional domains e.g., the Kp4-toxin-like and cerato-platanin-like proteins (see below) that can share $>60 \%$ similarities in the respective group.

Overall, the genes encoding the 190 SSCPs appeared to be distributed randomly in the genome as they can be found in all four chromosomes with comparable numbers $(55,64,40$, and 31 on chromosome 1, 2, 3, and 4, respectively). However, two "clusters" were found near the distal ends of chromosome 1, each containing seven and eight SSCP genes located within a short genomic region $(\sim 250 \mathrm{~kb})$. Interestingly, the cluster near the $5^{\prime}$ end of chromosome 1 harbored three immediately adjacent genes encoding the highly similar Kp4 toxin-like proteins (see below), suggesting that some SSCP genes may have arisen through gene duplication.

Detection of extracellular SSCPs secreted by $\boldsymbol{F}$. graminearum in vitro. An in vitro secretome of $F$. graminearum was obtained by isolating fungal culture filtrate proteins from liquid $\mathrm{MM}$ inoculated with the PH-1 isolate at two different time points ( 8 and 14 days postinoculation, respectively). The fungus grew well in this nitrogenlimiting medium (which mimics conditions during pathogenesis) as indicated by the congregated pink-colored mycelia seen at the bottom of the flask on the day of collection (Fig. 2A, left). About $25 \mathrm{ml}$ culture supernatants, which appeared to be faint pink (Fig. 2A, middle), was collected at each time point. The pink color disappeared after passing the supernatants through a $0.45 \mu \mathrm{m}$ syringe filter (Fig. 2A, right), suggesting that it was likely due to the presence of fragmented mycelia that were not pelleted during centrifugation. About $1 \mathrm{ml}$ of concentrated culture filtrate protein sample per time point was finally obtained and confirmed to be free of microbial contamination (data not shown). SDS-PAGE analysis indicated that the samples contained proteins with molecular masses ranging mainly from 10 to $150 \mathrm{kDa}$ (Fig. 2B). The concentration of the total proteins in the final culture filtrate samples was estimated at $\sim 10 \mathrm{ng} / \mu \mathrm{l}$.

Nanoscale liquid chromatography tandem mass spectrometry (nanoLC-MS/MS) analysis of the trypsin-digested culture filtrate proteins revealed that this liquid MM-based in vitro secretome consists of at least 250 proteins with amino acid sequences matching the annotated proteins encoded in the genome of F. graminearum (data not shown). These extracellular proteins included 25 that are among the identified 190 SSCPs described above (Fig. 1), suggesting that at least $13 \%$ of the total SSCPs are indeed produced and secreted extracellularly by the fungus in vitro under the conditions used in this study (Fig. 2A). These 25 true extracellular SSCPs consisted of 76 to 195 aa with 2.2 to $12.3 \%$ cysteine residues. Molecular masses were predicted to be 8.8 to $20.3 \mathrm{kDa}$. A majority (17) was found to be acidic with isoelectric points (pI) ranging from 4.0 to 6.9 (Table 1). Transcriptional analysis suggested that 23 extracellular SSCPs are expressed in planta with at least six up-regulated during the development of FHB (see below).

Sequence analysis of $F$. graminearum SSCPs with homologies to proteins known to be involved in plant pathogenesis. BLAST $\mathrm{CD}$ searches and amino acid sequence alignments suggested that 12 SSCPs contain functional domains conserved in fungal proteins known to be involved in plant pathogenesis (Table 1). Six SSCPs (FGSG_00588, 02077, 02181,03573,03599, and 08554) contained a CFEM domain (pfam05730, for "Common in several Fungal Extracellular Membrane proteins") represented by the ACI1 protein identified from the rice blast fungus Magnaporthe grisea (Kulkarni et al. 2003). The CFEM domain consists of $\sim 70$ amino acids (corresponding to residues 35 to 104 in FGSG_02181), and features eight conserved cysteine residues (Fig. 3A). Two SSCPs (FGSG_03960 and 01831) contained domains characteristic of fungal hydrophobins known to be involved in fungal pathogenesis (Bayry et al. 2012). FGSG_03960 contained a fungal class I hydrophobin domain (pfam01185; e.g., M. grisea MPG1 protein [Talbot et al. 1993]) that consists of $\sim 80$ amino acids (corresponding to residues 94 to 170 in FGSG_03960), including seven conserved cysteine residues (Fig. 3B). FGSG_01831 contained a fungal class II hydrophobin domain (pfam06766; e.g., Verticillium dahlia VDH1 protein [Klimes and Dobinson [2006]) that consists of $\sim 60$ amino acids (corresponding to residues 30 to 90 in FGSG_01831), featuring eight conserved cysteine residues (Fig. 3C).

Interestingly, two SSCPs (FGSG_05341 and 11318) were found to contain homology to Ecp2, a well-known fungal effector originally identified from the tomato pathogen C. fulvum (Van den Ackerveken et al. 1993). FGSG_05341 (189 aa) and FGSG_11318 (135 aa) did not show significant overall similarity to Ecp2, but contained the Ecp2-specific domain (pfam14856, Hce2 super family/pathogen necrosis-inducing factor), which consists of $\sim 90$ amino acids (corresponding to residues 59 to 166 in FGSG_05341), including four conserved cysteine residues embedded in motif-like sequences (Fig. 3D). Also relating to necrosis-inducing activity, two SSCPs (FGSG_10212 and 11205) had homology to cerato-platanin, a necrosis-inducing phytotoxin originally identified from the plane tree canker stain fungus Ceratocystis fimbriata (Pazzagli et al. 1999). Database searches indicated that cerato-platanin-like proteins are widely spread among ascomycetes, including many plant pathogens. These proteins all contain the cerato-platanin domain (pfam07249), which consists of $\sim 120$ amino acids (corresponding to residues 19-137 in FGSG_10212) featuring four conserved cysteine residues (Fig. 3E). FGSG_10212 and 11205 are likely paralogues since they share $72 \%$ amino acid similarity.

Three SSCPs described above, FGSG_02077 and 08554 (CFEMcontaining) and FGSG_11205 (cerato-platanin-like), were also found in the in vitro secretome (Table 1).

Sequence analysis of $F$. graminearum SSCPs with homologies to other proteins of interest. In addition to the 12 SSCPs mentioned above, sequence analysis also indicated that five SSCPs contain homologies to proteins that have established crystal structures but have not been directly associated with fungal pathogenicity/virulence on plants in previous studies (Table 1). FGSG_00569, was found to belong to the CAP (Cysteine-rich secretory proteins, Antigen 5, and Pathogenesis-related 1 proteins) family (pfam00188) that includes the group 1 plant pathogenesisrelated (PR-1) proteins (van Loon and Van Strien 1999). The CAP domain consists of $\sim 130$ amino acids (corresponding to residues 31-159 in FGSG_00569). In PR-1 proteins this domain adopts a unique three-dimensional structure with four $\alpha$-helices and four $\beta$-strands (Szyperski et al. 1998). When compared with plant PR-1 proteins, FGSG_00569 showed $\sim 50 \%$ similarity to the wheat PR-1-7 and the tomato PR-1A proteins, both of which belong to acidic PR-1 proteins (Lu et al. 2011). FGSG_00569 was also predicted to be an acidic protein $(\mathrm{pI}=4.7)$ and contain conserved residues for PR-1-specific secondary structures and active sites; some 
insertions/deletions were found in loops connecting secondary structure elements (Fig. 4A).

Three SSCPs (FGSG_00060, 00061, and 00062) were found to belong to the Kp4 Superfamily (pfam09044), as represented by the $\mathrm{Kp} 4$ toxin originally identified from the corn smut fungus Ustilago maydis. Kp4 toxin is a small protein (127 aa) featuring four $\alpha$-helices and five $\beta$-strands (Park et al. 1994) and has been shown to be a calcium channel blocker disruptive to eukaryotic cells (Gage et al. 2001). The three $F$. graminearum Kp4-like proteins showed moderate overall similarity (50 to $55 \%$ ) to $\mathrm{Kp} 4$, but contained five conserved cysteines and other residues of major secondary structure elements (Fig. 4B).

FGSG_12160 was found to contain homology to the glycosyl hydrolase family 61 (pfam03443) as represented by the Cel61B protein, a probable endoglucanase originally identified from the cellulose-degrading ascomycete Trichoderma reesei that features one major $\alpha$-helix and $13 \beta$-strands (Karkehabadi et al. 2008) and is conserved among ascomycetes. FGSG_12160 differed from other Cel61B-like proteins in that, although having four conserved cysteine residues, it lacked amino acids at the $\mathrm{C}$-terminus that
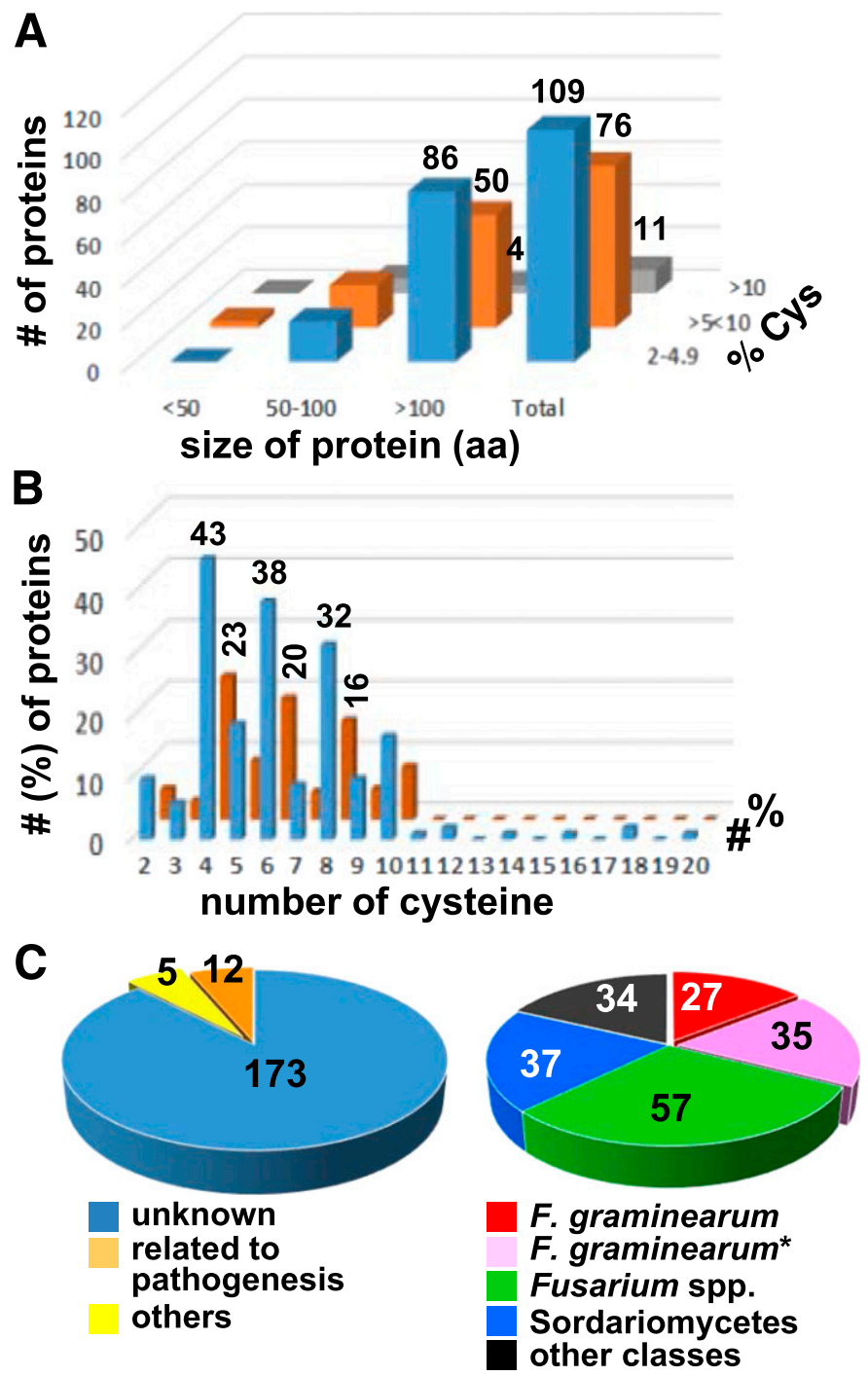

Fig. 1. An overview of small secreted cysteine-rich proteins (SSCPs) identified in the genome of Fusarium graminearum. A, Distribution of protein size and percentage of cysteines. B, Distribution of actual numbers of cysteines. C, Numbers of proteins classified based on the predicted functions (left) and overall similarity to other species of ascomycetes (right). F. graminearum*: found in $F$. graminearum and F. pseudograminearum only. Characteristics of individual SSCPs are given in Supplementary Table S1. comprise the last two beta strands ( $\beta 12$ and $\beta 13)$ at positions 189 to 205 in Cel61B (Fig. 4C).

Determination of in planta expression patterns of selected SSCPs. Plant assays indicated that the $F$. graminearum $\mathrm{PH}-1$ isolate caused typical FHB symptoms on the susceptible hexaploid wheat (cultivar Grandin) within about 2 weeks. The fungus caused disease symptoms visible as partially bleached spikelets on the infected wheat spikes as early as $48 \mathrm{~h}$ postinoculation (hpi) (Fig. 5, spike 4 , indicated by arrow). Such disease symptoms spread to most spikelets at 72 hpi (Fig. 5, spike 5, indicated by arrow). The infected wheat heads were largely or completely bleached at later stages of disease development, i.e., 8 to 14 days postinoculation (dpi) (Fig. 5, spike 6 and 7). No disease symptoms were observed on the control plants that were treated with water only (Fig. 5, spike 8).

For transcriptional analysis, mRNA samples were isolated from infected wheat plants at seven different time points as shown in Figure 5. RT-PCR was performed for 39 SSCPs, including all 17 proteins that contain conserved domains and 22 additional proteins detected in the in vitro secretome (Table 1). Transcripts of 34 SSCPs were detected in planta with different expression patterns (see below), suggesting that a majority of the identified SSCPs may be associated with the development of FHB in wheat. Transcripts of the remaining five SSCPs, including two CFEM domain-containing (FGSG_02181 and 03573), one hydrophobin-like (FGSG_03960), and two proteins of unknown functions (FGSG_00129 and 06597), were not detected at any stages of infection, suggesting that some SSCPs are dispensable for FHB. Transcripts of FGSG_02181, 03573, and 03960 were not detected in vitro either (Table 1), suggesting that some predicted SSCPs may not be actually produced by the fungus.

Most of the SSCPs detected in planta fell into two major groups. One group included 11 SSCPs whose transcripts were detected in all stages of infection and also in fungal cultures with equal expression levels (Fig. 6, left, panels 2 to 12). The other group included 15 SSCPs whose transcripts were detected in planta and found to be upregulated in comparison with those in fungal cultures (Fig. 6, right). In addition, three SSCPs were found to be expressed in planta at certain stages with expressed levels equal to those in vitro, but downregulated at other time points (Fig. 6, left, panels 13 to 15). The remaining five SSCPs (FGSG_06712, 08164, 09712, 10585, and 10603) were found to be expressed only at very low levels (Table 1). The 11 "constitutively" expressed SSCPs (Fig. 6, left) included five proteins that contain conserved domains, i.e., FGSG_00588, 02077, 08554 (CFEM-like, panels 2 to 4), FGSG_10212 and 11205 (cerato-platanin-like, panels 5 to 6 ), and six with unknown functions identified in the in vitro secretome (panels 7 to 12 ).
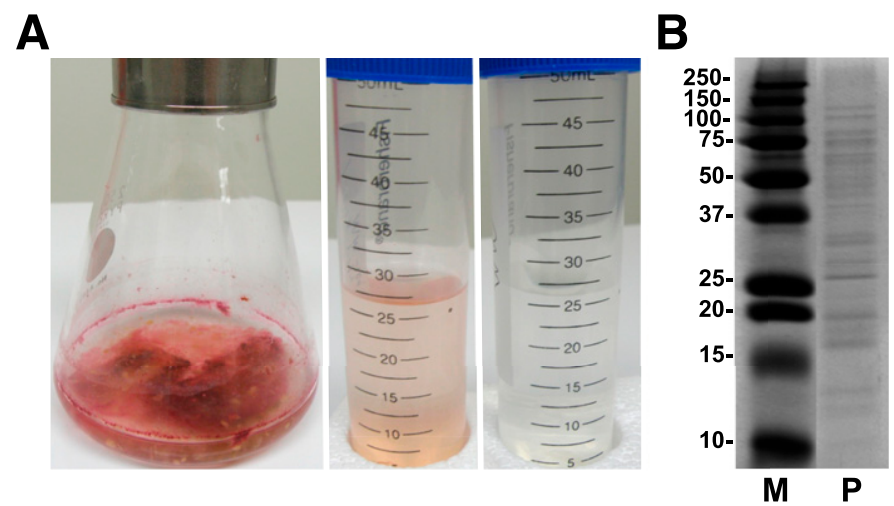

Fig. 2. Isolation of fungal culture filtrate proteins for in vitro secretome analysis. A, Fungal culture in liquid minimal medium (left), original pinkcolored (middle) and filtered colorless (right) supernatants $(\sim 25 \mathrm{ml})$ isolated 8 days postinoculation. B, Sodium dodecyl sulfate-polyacrylamide gel electrophoresis showing $F$. graminearum culture filtrate proteins (P, $30 \mu$ per lane) concentrated from the clear supernatant shown in A. M, protein markers with respective molecular masses indicated on the left (in $\mathrm{kDa}$ ). 
Eight SSCPs in this group (panels 2 to 9) showed expression levels nearly equal to those of the housekeeping actin protein used as an internal control (top panel). The other three showed relatively lower expression levels (panels 10 to 12). The 15 upregulated SSCPs (Fig. 6, right) included nine proteins that contain conserved domains, i.e., FGSG_11318 and 05431 (Ecp-2-like, panels 1 and 4), FGSG_03599 (CFEM-like, panel 3), FGSG_00060, 00061 and
00062 (Kp4-like, panels 10, 14 and 9), FGSG_00569 (PR-1-like, panel 11), FGSG_01831 (hydrophobin-like, panel 12), and FGSG_12160 (glycol_61 family, panel 13), and six with unknown functions identified in the in vitro secretome (panels 2, 5 to 8, and 15).

The starting point of up-regulation of individual SSCPs was noticeably different. For example, FGSG_11318 was up-regulated starting as early as 4 hpi (Fig. 6, right, top panel). FGSG_04074 and
$\mathbf{A}_{\text {MaAC11 }}$

FGSG_00588

FGSG_02077

FGSG_02181

FGSG_03573

FGSG 03599

FGSG_08554

CohCCF 36376

ChEMD89003

B $M g M P G 1$

FGSG_03960

FaKIL85004

NhXP003040123

AnEHA24682

ChABY 48863

CVQ00367

$\mathbf{C}_{\mathrm{VDYDH} 1}$

FGSG_01831

FaKIL 90274

MgXP 003717406

CofXP007598074

BcXP001560180

SsXP001589527

D

FGSG_05341

FGSG_11318

ChEMD94398

CogEFQ33725

StXP008023345

VaXP003001533

CFECP2

FGSG_05341

FGSG_11318

ChEMD94398

CogEFQ33725

StXP008023345

VaXP003001533

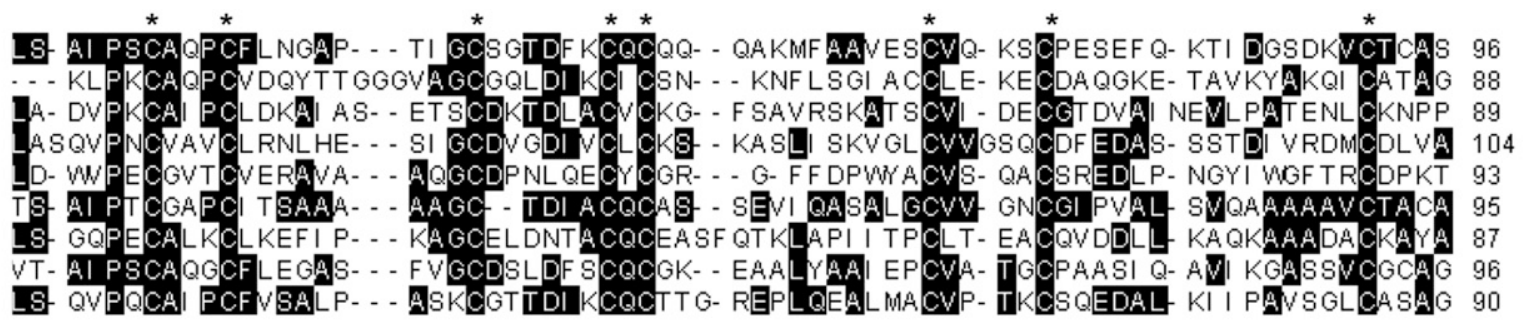

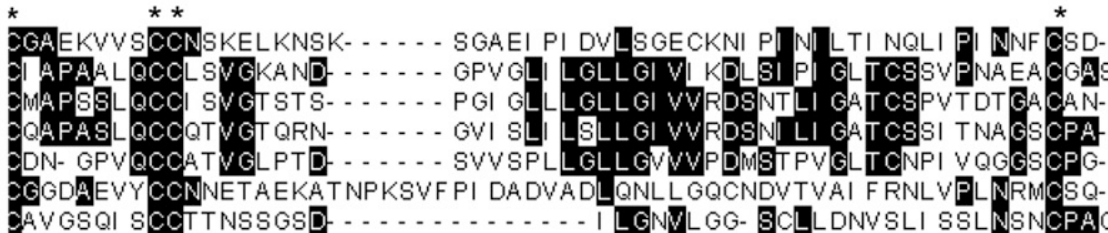
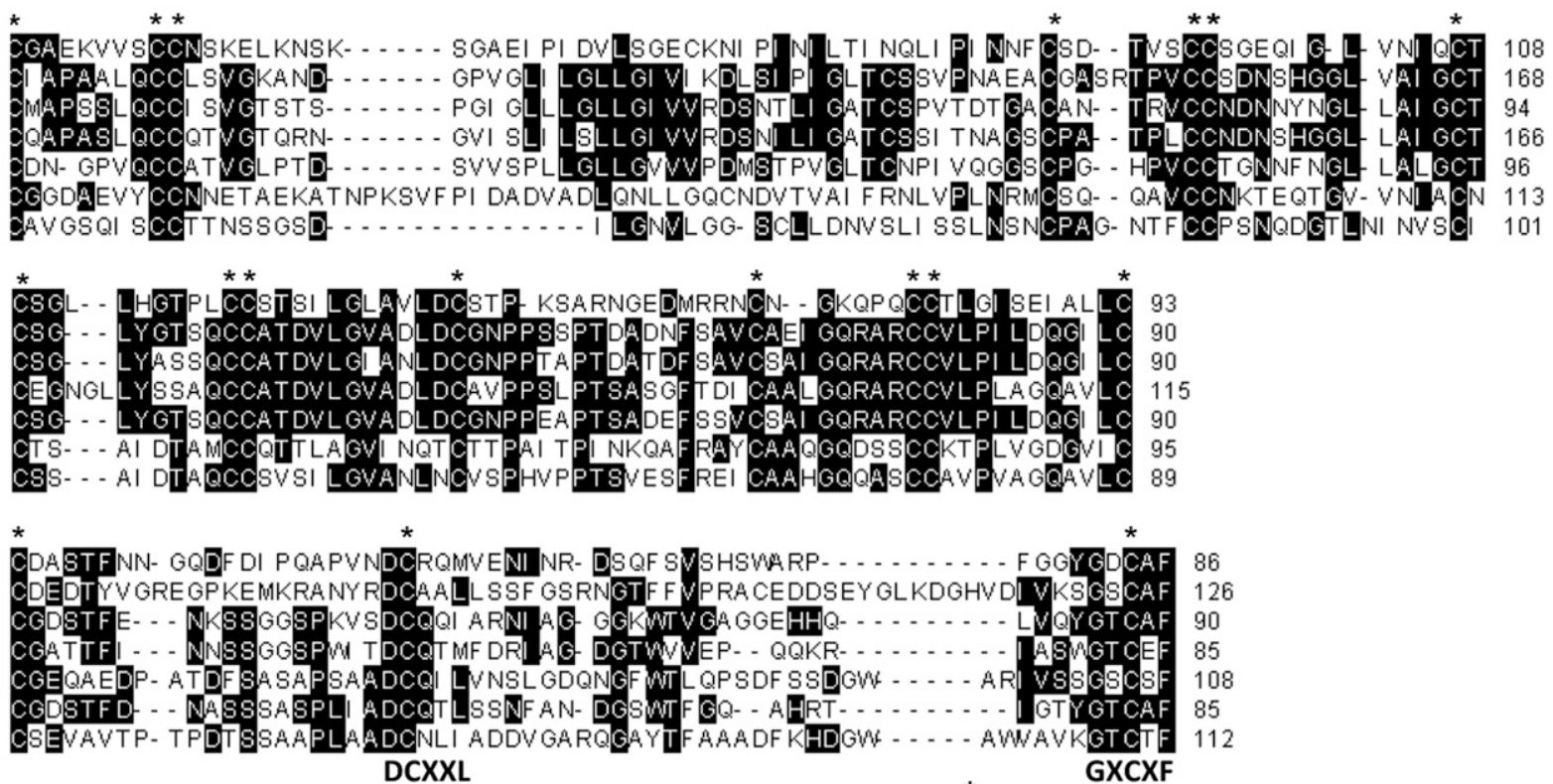

\section{DCXXL}

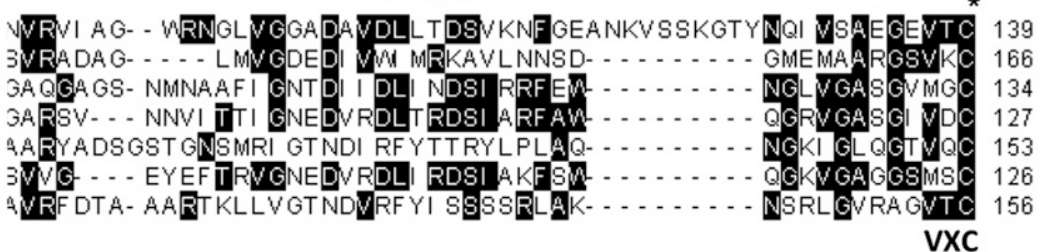

E cpcerato-platanin

FGSG_11205

FGSG_10212

BcXP001559499

ChEMD92796

CohCCF70879

MgXP003710181
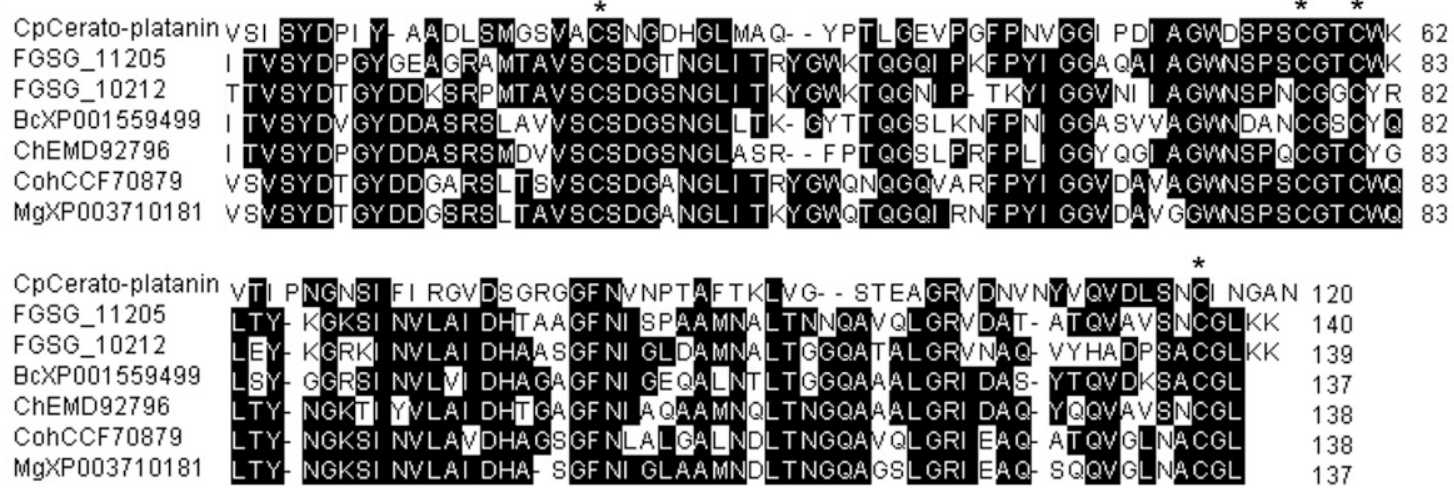

Fig. 3. Amino acid sequence alignments showing pathogenesis-related domains identified in 12 Fusarium graminearum small secreted cysteine-rich proteins (SSCPs). Identical residues are presented as white letters in a black background. Asterisks at top of the alignment indicate conserved cysteine residues. Numbers on the right indicate the positions in the full-length proteins. A, CFEM domain (pfam05730). B, Fungal hydrophobin (pfam01185). C, Fungal hydrophobin 2 (pfam06766). D, Hce2 superfamily/pathogen necrosis-inducing factor (pfam14856). Three motif-like sequences are indicated at the bottom. E, Cerato-platanin (pfam07249). Species abbreviations (followed by defined protein name or GenBank accession number of the aligned proteins): An, Aspergillus niger; Bc, Botrytis cinerea; Cf, Cladosporium fulvum; Ch, Cochliobolus heterostrophus; Cog, Colletotrichum graminicola; Coh, Colletotrichum higginsianum; Cp, Ceratocystis platani; Cv, Cochliobolus victoriae; Fa, Fusarium avenaceum; Le, Lycopersicon esculentum; Mg, Magnaporthe grisea; Nh, Nectria haematococca; Ss, Sclerotinia sclerotiorum; St, Setosphaeria turcica; Ta, Triticum aestivum; Va, Verticillium alfalfa; and Vd, Verticillium dahliae. 
A

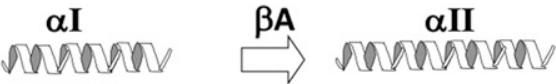

$\stackrel{\beta B}{\longrightarrow}$

TaPR-1-7

LePR-1A

FGSG_00569

FaKIL95092

CPCCE31409

VaxP003003894

NAARADVGLGEVT MOATVAAFA GDYADQRRGDCQL - I HTPDGR- . PYGENLVGGGG - . . . . . . TEWTA 91 NDLRSS GVVPLE MOEKLAAY AYYDWA VORKEDCNYRQHST G - . . . PYGENI FWQLY . . . . . . . . AETPA 98 MEARRAAGLHELAMOTSLAOSA QSMADKLAEGE- - VPHGYSLAQYPVSGEAI YEEETATDCVGQSFEATL 102 NDERRNSGHSEL MORALRDSALLRACQLAKSHLTDHHRPSGE - ARYMEKVATCHS PPMTHQSMAMTL 111 OAROAHGVPGLAMOTGLEAYAQF MANEMA SGRSRF EHAQGPN- RPSQGENLYEQSAGQCDA- - AYDNPL 98

TaPR-1-7

LePR-1A

FGSG_00569

FaKIL $\overline{9} 5092$

CpCCE31409

VaXP003003894

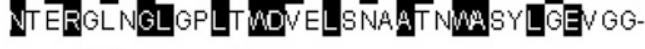

$\alpha$ III

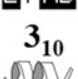

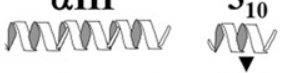
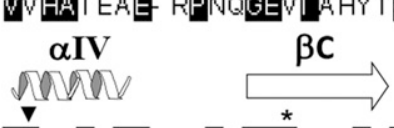

$\beta D$

ATDAVNSW - SEKQYYDHDSNT CSAP - - EGESCGHYTQVWRDSTAL GCAR- WVCDSGDGVFI I CSYNP 155 AT GI VKKMF - DEKKKF DEVNNVCKCKPEKEGCECGHY LNI WNKTTTKVGCSGNV CKNQKGAYVVCSYDP 166 L QSAVGNM HKWEAEP. .............. GVETKT NHDA- CMASTAEYVGCGKAFNTHSDD- EEKKCKF YD 157 LOTAANSMLFVGKQST. . . . . . . GDTVKDAQF DMG HRDHCLSPSATKIGCAR- TQNLTECMAFVVCQFDS 172 LOTGMHAML SQEHF YT - . . . . . . GQPI TTGHEPMLHWFVVYHDEDRM-CEGVCLVGAI .. QVLRCVPI H 157

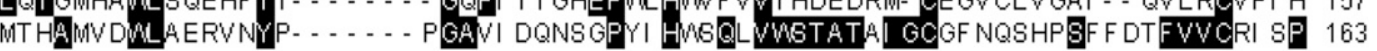

B

UmKp4

FGSG_00060

FGSG_00061

FGSG_00062

FWEWG 41394

a1

$\alpha 2$

$\stackrel{\beta 1}{\longrightarrow}$

$\underset{*}{\beta 2}$

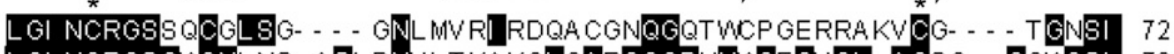

LGI NCRGSGNCNI NS- ASLDNVLTKAKQLOARGQGDHHMGEGVQI-ACSG- GQMGSI 70

LGI NCRGSGLCSGGA- GNLI NLKAI VDNI QPR - - DRHYETGQQV-ACT - - - - GDT 65

LGI NCRGSGFCDLTFGSSI GDI QDQI GILVADGQGDRHFDT GAOI- ACTQ- - GNOGSI 71

LGI NCRGSGLCNLSFGPSI QNI QDQI GNMI ADGQGDRFF GDGAQV-ACTS- GDAGSI 71

CogXP008098140 LGI NCRGSGNCNSDN- - - F QGAASELAALI RSI PDGRMENNGQQI ACF SRMGVGGG 72

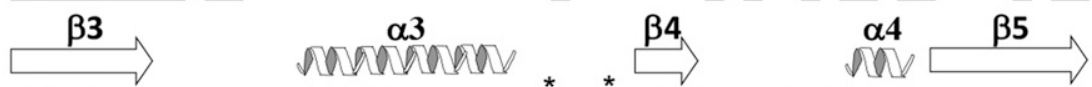

UmKp4 SAYVQSTNNCI SGTEACRHLTNLVNHGCRVC̈GSDPL- YAGNDVSRGQLTVNYVN- SC 127

FGSG_00060 CAFFQSG-ASGNTDRAVELI QGI LDHGCTQCGSIPT - EEGNNVDNGQLTVNYVENPC 134

FGSG_00061 CAFF QSS- ATGTADDVSWALQALLDHGCKKCGSVPM- - QDGNNVDDGQLTVNYVSDPS 125

FGSG_00062 CAFYQSG ASGSARDAFGHI QQI I DHGCSLCGSVPT - QEGNNVDDGQLTVNYVSDPC 133

FWEWG 41394 CAFFQSG- ASGTANDAF HYMOEI I DHGCKLCGSVPT - QPGNNVANGQLTVNAVSKPC 133

CogXP008098140 CAFYQNT - GGMOAKKAKDI VGHLVSHGCKVCGSVPTGF PGSNDVA QGQLTFNYVAKPC 139

C

TrTrCel61日

FGSG_12160

NhXP00 03045244

BcCCD50451

ChEMD97281

SP

$\stackrel{\beta 1}{\square}$

Thiviviv

$\beta 3$

MKSCAI LAALGCLAGSVLGHGQVONFTI NO- - OYNGGFI LDYYYQKQNTGHFPNVAGWNAEDLD 62 - - MHI SLSLLCTAALAAAHGYVETATI GGQTYQFYNPYQDPYMNPLPKRI SRAII PGNGPVEDVT 62 - MRCI LSLLSSVALVAAHGYVESATI GGKEYEFYNPNVDPYSNPVPERI SRPI PGNGPVEDI S 62 MHLKTF SNLLVF VATVAAHGYVDNVTVNGI LYTGYQPNSDPYYATPPPRI IRPVQGNGPI TDLT 64 - MKYLLPTLGLAATAAAHGYVSNATI GGKDYTFYQPYQDPYTTGV-KRI SRPI QGNGPVEDVT 61 COGXP008095522 . - MOIAACI LGFAALVAGHGYVDNATI GG - - TYYQPYSDPYI NPLPKRI SRPI QGNGPVESVT 59

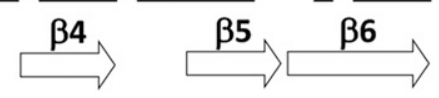

$\beta 7$

TrTrCel61日
FGSG_12160
NhXP003045244
BcCCD50451
ChEMD97281

CogXP008095522

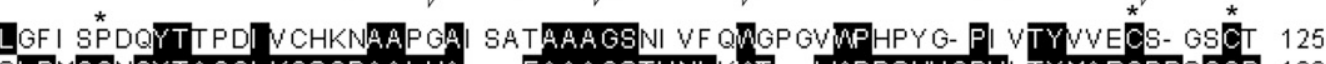
SI DMQCNGYTAGGI KGSQPAALHA - - EAAAGSTVNLKMT - LMPDSHVGPVLTYMARCPDSGCD 122 LI DLQCNGYTAGGVKGSQPAALHA - - EAEAGSTVNLRWT - LMPDSHVGPVLTYMARCPDEGCD 122 LI DLQCGGYTEGGI VGSQPANLTAG- - PVAAGSTVSLRWT- LMPDSHSGPVI TYMAKCPATGCS 125 SDLQCGGYTAGGFKGSSPAALHA - - EAAAGSEVKLYMT - LMPESHVGPSI TYMARCPDTGCD 121 LI DLQCGGYTAGGI SGSQPAALHA-

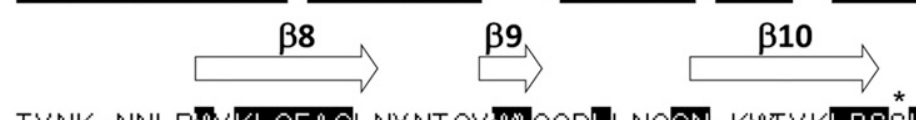

$\beta 11$

TrTrCel61日

FGSG_12160 NhXP003045244

BCCCD50451

ChEMD97281

Cog XP008095522

VTLRWT

TVNK- NNLRMVI QEAGI NYNTQVMAQQDLI NQGN- KWTVKI PSSLRPGNYVFFRELLAAHGASS 188 AWMPGTEKWMF KI QEAGRDGTSNNMA SSVI MKKAGNSGVNYTI PQCI KP GYYLEPSS- TLDAISS 185 AMEPASEKWMF KVQEAGREGTSNMMAATSLMKADNEGI DYTI PSCLKPGYYLVRHEI IALHAAYS 187 TYVPGTAA WMF KI QATGRI GNTT MGDTPLKTA GN- SYSYTI PSCLSAGSYIVRHEI LALHAAMT 189 AYMPESDAVMF KVOEEGRGGTSNKMASDAI RVAGG- YLSYTI PKCI AAGYYLVRHEVLALHSAYK 185 DNOPGTSAVMF KI QEGGRT GTSNTMASSPLMAGS-I AOYTI PSCLKPGYYLVRHETI ALHAASS 183

Fig. 4. Amino acid sequence alignments showing other conserved domains identified in five Fusarium graminearum SSCPs. A, CAP (Cysteine-rich secretory proteins, Antigen 5, and Pathogenesis-related 1 proteins) family (pfam00188). Secondary structures ( $\alpha$, alpha helix; $\beta$, beta strand) are drawn based on plant PR-1 proteins (Lu et al. 2011). Triangle indicates known active sites. B, Kp4 Superfamily (c107601). Secondary structures are drawn based on the Kp4 toxin of Ustilago maydis (Park et al. 1994). C, Glycosyl hydrolase family_61 (pfam03443). Secondary structures are drawn based on the Cel61B protein of Trichoderma reesei (Karkehabadi et al. 2008). Downward arrow indicates the position at which FGSG_12160 lacks the C-terminal residues corresponding to $\beta 12$ and $\beta 13$ of Cel61B (positions 189 to 205, not shown). SP, signal peptide sequence. Species abbreviations: Bc, Botrytis cinerea; Cf, Cladosporium fulvum; Ch, Cochliobolus heterostrophus; Cog, Colletotrichum graminicola; Coh, Colletotrichum higginsianum; Cp, Claviceps purpurea; Fa, Fusarium avenaceum; Fv, Fusarium verticillioides; Le, Lycopersicon esculentum; Nh, Nectria haematococca; Ta, Triticum aestivum; Tr, Trichoderma reesei; Um, Ustilago maydis. 
FGSG_03599 were up-regulated starting at $12 \mathrm{~h}$ (panels 2 and 3). FGSG_05431 and seven other proteins were up-regulated starting at $24 \mathrm{~h}$ (panels 4 to 11), FGSG_01831 and 00061 (panels 12 and 13) at $48 \mathrm{~h}$, and FGSG_00061 and 04805 (panels 14 and 15) at $72 \mathrm{~h}$, respectively. The expression levels of most up-regulated SSCPs appeared to correlate with the development of FHB. For example, transcripts of FGSG_05341 (Ecp-2-like, panel 4), FGSG_00062 and FGSG_00060 (Kp4-like, panels 11 and 12) were all up-regulated as early as $24 \mathrm{~h}$, but expression levels increased more obviously from $72 \mathrm{~h}$ to 14 days while the FHB disease symptoms progressed (Fig. 5, spikes 5 to 7). Interestingly, the up-regulation of some SSCPs appeared to be "transient." For example, FGSG_04661 (protein of unknown function, panel 7) was up-regulated sharply at $24 \mathrm{~h}$ but apparently down-regulated at later stages ( $72 \mathrm{~h}$ to 14 days). The endoglucanaselike protein (panel 13) was up-regulated sharply at $48 \mathrm{~h}$ but downregulated afterward at all later stages. The transcripts of a majority of these up-regulated SSCPs were not detectable or were detected at very low levels in the mRNA samples isolated from fungal cultures under the same PCR conditions (Fig. 6, right, lanes 9), indicating that they are preferentially expressed in planta.

\section{DISCUSSION}

SSCPs produced by plant-pathogenic fungi have attracted broad attention from the research community in the past decade. The functions of SSCP-derived effectors in manipulating disease/resistance in host plants have been demonstrated for a number of ascomycete pathogens, including those in biotrophic, hemibitrophic, and necrotrophic pathosystems (reviewed by Oliver et al. 2012; Stergiopoulos and de Wit 2009), but have not been well explored in F. graminearum whose genome is known to encode a large number of SSCPs (Brown et al. 2012; Krijger et al. 2014; Sperschneider et al. 2015).

In this study, we analyzed a total of 190 SSCPs encoded in the genome of $F$. graminearum that were identified using criteria that limit the size of predicted mature proteins to $\leq 200$ aa and the content of cysteine residues to $\geq 2 \%$. We used these criteria because they reflect the "consensus" of known SSCP-derived fungal effectors. For example, all $10 \mathrm{Avr} / \mathrm{Ecp}$ proteins identified from C. fulvum (Stergiopoulos and de Wit 2009) contain 28 to 199 aa with 2.8 to $21 \%$ cysteine residues. Similarly, all but one of the seven SIX proteins identified from $F$. oxysporum f. sp. lycopersici (Lievens et al. 2009) contain 144 to 200 aa with 3.5 to $5.8 \%$ cysteine residues. The number of SSCPs identified in this study is comparable to the number of SSCPs identified from another ascomycete pathogen of cereal crops, the southern corn leaf blight fungus Cochliobolus heterostrophus (180 SSCPs), by Condon et al. (2013), who applied the same criteria. However, the number of SSCPs identified is much less than previously reported for F. graminearum (>300 SSCPs) by Krijger et al. (2014) and Sperschneider et al. (2015), who applied different criteria, i.e., $\leq 300 \mathrm{aa} / \geq 4$ cysteines. Thus, our selection criteria reduced the number of $F$. graminearum SSCPs prioritized for further analysis by more than one hundred. On the other hand, there are a total of 16 SSCPs in our inventory list that were excluded in previous studies because they all contain only two to three cysteines but nevertheless still have a cysteine content $>2 \%$ due to the very small size of the protein (Fig. $2 \mathrm{~B}$ ).

Identification of extracellular SSCPs that are secreted by $F$. graminearum in planta is a challenging task. A previous proteomics study has shown that up to $50 \%$ of "extracellular" proteins identified in apoplastic fluids vacuum-extracted from $F$. graminearum-infected wheat heads lack N-terminal SP sequences (Paper et al. 2007), thus making it difficult to determine if they are true extracellular proteins. In this study, we selected in vitro cultures as the source from which to identify true extracellular SSCPs because it is known that microbial culture filtrates are rich in extracellular proteins (Rosenkrands and Andersen 2001). To enrich SSCPs that are likely secreted by the fungus in planta, we used a simple nitrogen-limiting medium that mimics the conditions of plant pathogenesis. Indeed, our transcriptional analysis confirmed that almost all 25 SSCPs detected in the in vitro secretome are expressed in planta (Table 1) including six with expression patterns correlating with the development of FHB (Fig. 6, right). We noticed that Paper et al. (2007) identified a total of 289 $F$. graminearum extracellular proteins (from as many as 13 different culture conditions plus some in planta samples), but did not mention any SSCPs in the secretome. Therefore, we examined all of these 289 proteins using the accession numbers given by the authors. We found 25 that are the same as those in our inventory list, including 10 that we detected in vitro using a single minimal medium. Furthermore, we found seven SSCPs in the 120 extracellular proteins identified from apoplastic fluids in the same study (Paper et al. 2007). These seven in planta SSCPs include FGSG_10212 and 11205 (cerato-platanin-like) and FGSG_00060 (Kp4-like) that we selected as candidate effectors based on conserved domain analysis (Figs. 3 and 4) and four proteins of unknown function (FGSG_04074, 04213, 04741, and 07988). FGSG_11205, 04074, and 04213 are among the 25 extracellular SSCPs that we detected in the in vitro secretome (Table 1). Therefore, we believe the minimal medium-based in vitro method we used in this study is practical and efficient for detection of extracellular SSCPs produced by $F$. graminearum including those secreted by the fungus in planta.

The data presented in this study provide important clues for selecting candidate effectors from the SSCPs encoded in the genome of $F$. graminearum. This fungus is known to be a "hemibiotrophic" pathogen, beginning subcuticular and intercellular growth at the early stages of infection and switching to intracellular necrotrophic growth approximately after 2 days postinoculation (Walter et al. 2010). Our transcriptional analysis revealed that at least 15 SSCPs are upregulated in planta, suggesting that these proteins may be involved in the development of FHB in wheat. Furthermore, more than half of these 15 SSCPs were noticeably up-regulated starting at 24 hpi (Fig. 6 , right). This may reflect the importance of these SSCPs in mediating the in planta transition from "biotrophic" to necrotrophic growth phases during the development of FHB. In addition, our sequence analysis (Figs. 3 and 4) suggested that more than half of the 15 up-regulated SSCPs contain functional domains that may be directly or indirectly associated with fungal pathogenesis. Therefore, we think it is plausible to select at least these 15 SSCPs as candidate effectors subject to further functional analysis.

While the potential functions of these candidate effectors are still to be investigated, the presence of conserved domains in certain SSCPs may provide some insight. For example, the CFEM domain (Fig. 3A) is conserved in ascomycetes. In M. grisea, the ACI1 protein (from which the CFEM domain was originally identified) is actually a glycosylphosphatidylinositol (GPI)-anchored membrane protein, which interacts with a fungal adenylate cyclase controlling appressorium formation, a critical step in the development of rice blast disease (Kulkarni et al. 2003). Our transcriptional analysis indicated that at least one of the CFEM domain-containing SSCPs (FGSG_03599) is likely involved in the development of FHB since it is apparently up-regulated as early as $12 \mathrm{hpi} \mathrm{(Fig.} \mathrm{6,} \mathrm{right,} \mathrm{panel} \mathrm{3).}$ Because all six $F$. graminearum CFEM domain-containing SSCPs lack a GPI-anchor motif or any transmembrane domains, it is unlikely that FGSG_03599 would function in the same way as ACI1 does. Alternatively, it might interact with host proteins instead and manipulate signal transduction pathways controlling defense responses.

The Kp4 protein (Fig. 4B) was originally purified from culture filtrates of the corn smut fungus $U$. maydis, and has been shown to be a killer toxin that inhibits fungal growth by blocking calcium uptake, although its toxicity to host plants has not been demonstrated (Gage et al. 2001). Our analysis suggested that all three $F$. graminearum Kp4-like SSCPs (FGSG_00060, 00061, and 00062) are up-regulated starting at $24 \mathrm{hpi}$ and their transcript levels increase while the disease progresses (Fig. 6, right, panels 9, 10, and 14). It will be interesting to investigate if these three Kp4-like proteins act as phytotoxins that contribute to the development of FHB. We noticed that these three Kp4-like proteins have been designated as Tox1, Tox2, and Tox3, 
respectively, in a previous transcriptome study (Lysoe et al. 2011), but no related functional analysis has been reported.

The CAP domain is conserved among several groups of eukaryotic proteins, particularly among the plant PR-1 proteins which are best known as hallmarks of hypersensitive response-related defense pathways (Van Loon and Van Strien 1999). Although the biochemical function of PR-1 is still unknown, the wheat PR-1-5 protein has been shown to enhance effector-induced necrosis on host plants ( $\mathrm{Lu}$ et al.

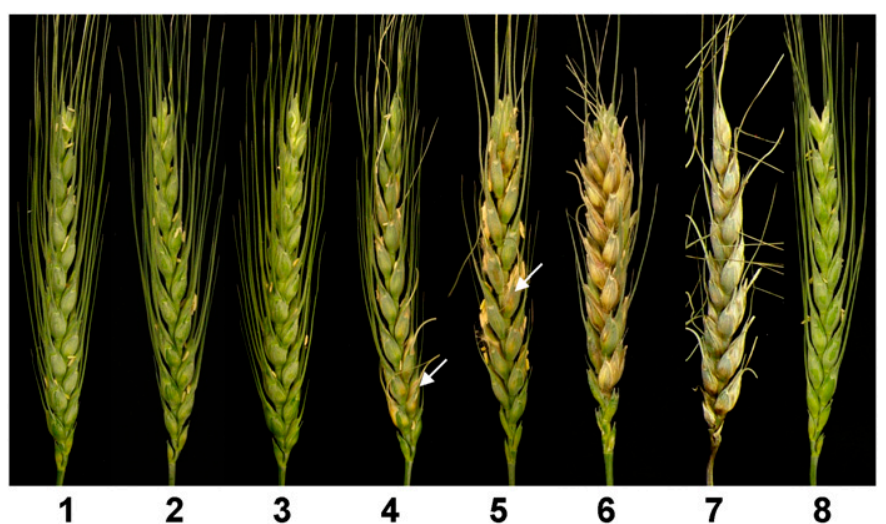

Fig. 5. Temporal patterns of Fusarium head blight development on susceptible wheat. Six-week-old plants of the hexaploid wheat Grandin were inoculated with macroconidial suspension $\left(1 \times 10^{7} / \mathrm{ml}\right)$ of Fusarium graminearum isolate $\mathrm{PH}-1$ and symptoms were recorded at (from 1 to 7 ) $4,12,24,48$, and $72 \mathrm{~h}$ postinoculation (hpi) and 8 and 14 days postinoculation (dpi), respectively. Spike 8: uninoculated control. One representative spike is shown for each time point. Arrows indicate disease symptoms observed on individual spikelets at the early stages of infection (48 to $72 \mathrm{hpi}$ ).
2014). In addition, one fungal PR-1 like protein identified from a human-pathogenic isolate of $F$. oxysporum has been shown to be involved in virulence (Prados-Rosales et al. 2012). Our analysis suggested that the CAP-domain-containing SSCP (FGSG_00569) is also up-regulated with the expression level peaking at $14 \mathrm{dpi}$ (Fig. 6, right, panel 11), at which time the infected wheat heads are completely bleached (Fig. 5). The fact that FGSG_00569 has apparent homology to a wheat PR-1 protein (Fig. 4A) raises the possibility that some $F$. graminearum SSCPs may act as molecular mimics of host proteins associated with defense responses in wheat.

The finding that the two $F$. graminearum SSCPs (FGSG_11318 and 05341) are homologous to Ecp2 is particularly interesting. These two Ecp2-like proteins are differentially expressed. FGSG_11318 is induced at the earliest stage of infection (4 hpi) with transcripts peaking at $24 \mathrm{hpi}$ and downregulated afterward (Fig. 6, right, top panel). In contrast, FGSG_05431 is up-regulated at 24 hpi with transcripts increasing progressively until 14 dpi (Fig. 6, right, panel 4). These different expression patterns may suggest that the two Ecp2-like proteins play different roles in fungal pathogenesis. Ecp2 was originally identified from the tomato pathogen C. fulvum (Van den Ackerveken et al. 1993) and its homologs were later identified from two additional species of Dothideomycetes in the genus Mycosphaerella, i.e., the banana black leaf streak fungus M. fijinesis and the wheat Septoria leaf blotch fungus $M$. graminicola. At least one of these two Ecp2 homologs has been shown to be functionally equivalent to the C. fulvum Ecp2, since it specifically induces hypersensitive response-like cell death in tomato carrying the cognate disease resistance $C f$-2 gene as Ecp2 does (Stergiopoulos et al. 2010). No Ecp2 homologs have been reported for F. graminearum or other species of Sordariomycetes in recent studies. On a related note,
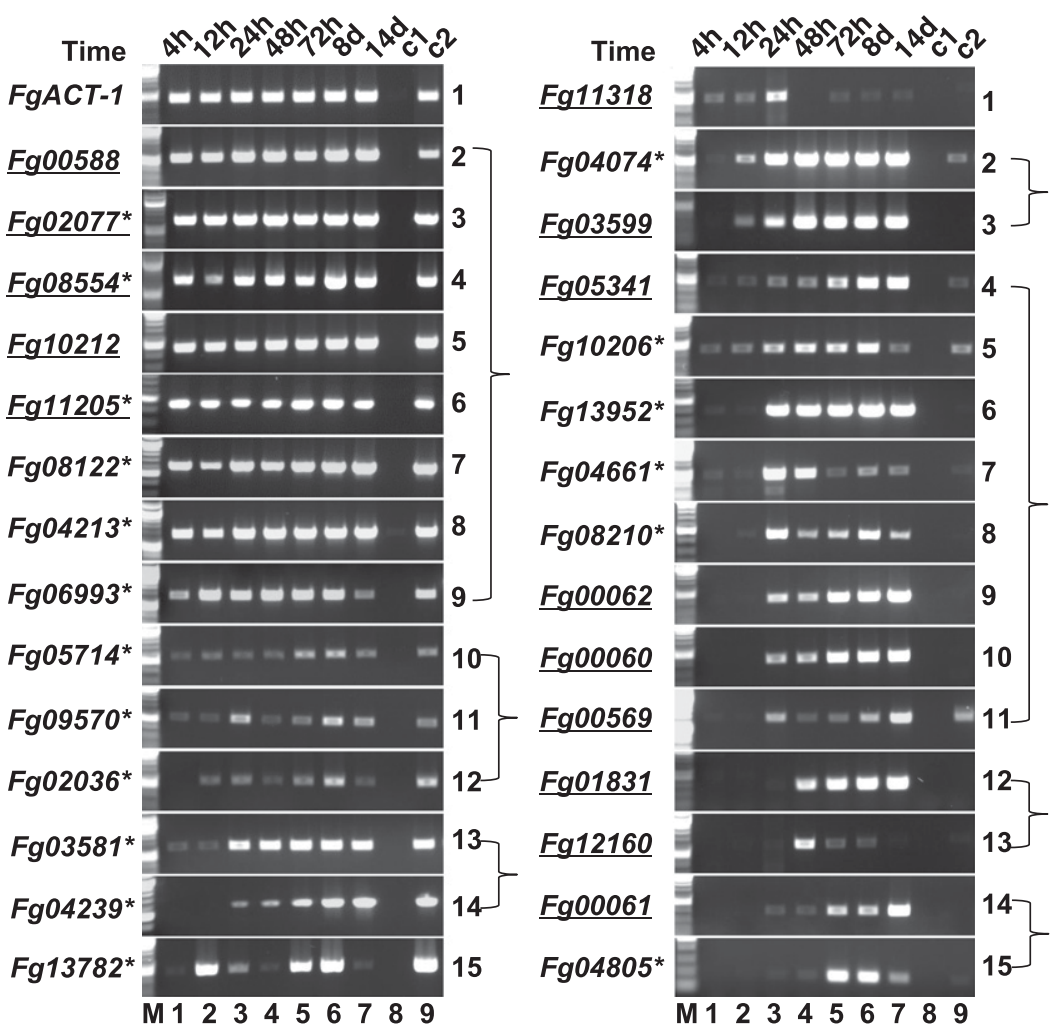

Fig. 6. In planta expression patterns of the mRNA transcripts representing 29 Fusarium graminearum small secreted cysteine-rich proteins (SSCPs). Ethidium bromide-stained $1 \%$ agarose gels were loaded with the amplicons of reverse transcription-polymerase chain reaction (RT-PCR) products from mRNA isolated from wheat heads inoculated with F. graminearum (isolate PH-1) as shown in Figure 5. Time points are indicated at the top. Lanes 8 and 9 were loaded with controls in which mRNA isolated from uninoculated wheat (c1) and an 8-day-old fungal culture in minimal medium (c2) were used for RT-PCR, respectively. For convenience, "FGSG" is replaced with "Fg" in the protein names. SSCPs detected in the in vitro secretome are indicated by asterisks. SSCPs containing conserved domains are underlined. Brackets indicate SSCPs with similar expression patterns (left) or up-regulated starting at the same time points (right). Primers used for RT-PCR and the size of amplicons are given in Supplementary Table S2. FgACT-1, F. graminearum actin gene (internal control). M, 100-bp DNA ladder. 
we have identified two wheat genes that encode leucine-rich repeats (LRR) type of disease resistance proteins homologous to Cf-2 (S. Lu, unpublished data). Whether the Ecp2-Cf-2 interaction in tomato has a mirror pathway in wheat that mediates FHB resistance remains to be determined.

Among the constitutively expressed SSCPs, the two cerato-plataninlike proteins (FGSG_10212 and FGSG_11205) are also of interest. Cerato-platanin was originally purified from culture filtrates of the plane tree canker stain fungus Ceratocystis fimbriata and has been shown to possess necrosis-inducing activity on host plants, although its biochemical function has not been resolved (Pazzagli et al. 1999). It should be feasible to test the roles of these two potential necrosisinducing proteins along with other candidate effectors by targeted gene deletion, heterologous expression, and host germplasm screening as we described recently for $C h$ ToxA, a host-selective necrosis-inducing toxin produced by C. heterostrophus (Lu et al. 2015).

In conclusion, through genomics, proteomics, and transcriptional profiling analyses of the SSCPs encoded in the genome of $F$. graminearum, we have identified at least 15 candidate effector proteins that may play roles in pathogenesis of this devastating disease of wheat. Further studies on these effector-like proteins may facilitate the discovery of novel pathogenicity/virulence factors from the fungus and an improved understanding of molecular mechanisms underlying FHB resistance.

\section{ACKNOWLEDGMENTS}

We thank C. Steen and M. Miller for technical assistance. This study was supported by USDA-ARS CRIS project 5442-21000-037-00D. Mention of trade names or commercial products in this publication is solely for the purpose of providing specific information and does not imply recommendation or endorsement by the U.S. Department of Agriculture. USDA is an equal opportunity provider and employer.

\section{LITERATURE CITED}

Bayry, J., Aimanianda, V., Guijarro, J. I., Sunde, M., and Latge, J. P. 2012. Hydrophobins-unique fungal proteins. PLoS Pathog. 8:e1002700.

Brown, N. A., Antoniw, J., and Hammond-Kosack, K. E. 2012. The predicted secretome of the plant pathogenic fungus Fusarium graminearum: A refined comparative analysis. PLoS One 7:e33731.

Brown, N. A., Urban, M., van de Meene, A. M., and Hammond-Kosack, K. E. 2010. The infection biology of Fusarium graminearum: Defining the pathways of spikelet to spikelet colonization in wheat ears. Fungal Biol. 114:555-571.

Buerstmayr, H., Ban, T., and Anderson, J. A. 2009. QTL mapping and markerassisted selection for Fusarium head blight resistance in wheat: a review. Plant Breed. 128:1-26.

Ciuffetti, L. M., Manning, V. A., Pandelova, I., Betts, M. F., and Martinez, J. P. 2010. Host-selective toxins, Ptr ToxA and Ptr ToxB, as necrotrophic effectors in the Pyrenophora tritici-repentis-wheat interaction. New Phytol. 187:911-919.

Condon, B. J., Leng, Y., Wu, D., Bushley, K. E., Ohm, R. A., Otillar, R., Martin, J., Schackwitz, W., Grimwood, J., MohdZainudin, N., Xue, C., Wang, R., Manning, V. A., Dhillon, B., Tu, Z. J., Steffenson, B. J., Salamov, A., Sun, H., Lowry, S., LaButti, K., Han, J., Copeland, A., Lindquist, E., Barry, K., Schmutz, J., Baker, S. E., Ciuffetti, L. M., Grigoriev, I. V., Zhong, S., and Turgeon, B. G. 2013. Comparative genome structure, secondary metabolite, and effector coding capacity across Cochliobolus pathogens. PLoS Genet. 9:e1003233.

Cuomo, C. A., Guldener, U., Xu, J. R., Trail, F., Turgeon, B. G., Di Pietro, A., Walton, J. D., Ma, L. J., Baker, S. E., Rep, M., Adam, G., Antoniw, J., Baldwin, T., Calvo, S., Chang, Y. L., Decaprio, D., Gale, L. R., Gnerre, S., Goswami, R. S., Hammond-Kosack, K., Harris, L. J., Hilburn, K., Kennell, J. C., Kroken, S., Magnuson, J. K., Mannhaupt, G., Mauceli, E., Mewes, H. W., Mitterbauer, R., Muehlbauer, G., Munsterkotter, M., Nelson, D., O’Donnell, K., Ouellet, T., Qi, W., Quesneville, H., Roncero, M. I., Seong, K. Y., Tetko, I. V., Urban, M., Waalwijk, C., Ward, T. J., Yao, J., Birren, B. W., and Kistler, H. C. 2007. The Fusarium graminearum genome reveals a link between localized polymorphism and pathogen specialization. Science 317:1400-1402.

Friesen, T. L., Meinhardt, S. W., and Faris, J. D. 2007. The Stagonospora nodorum-wheat pathosystem involves multiple proteinaceous host-selective toxins and corresponding host sensitivity genes that interact in an inverse gene-for-gene manner. Plant J. 51:681-692.

Gage, M. J., Bruenn, J., Fischer, M., Sanders, D., and Smith, T. J. 2001. KP4 fungal toxin inhibits growth in Ustilago maydis by blocking calcium uptake. Mol. Microbiol. 41:775-785.
Goswami, R. S., and Kistler, H. C. 2004. Heading for disaster: Fusarium graminearum on cereal crops. Mol. Plant Pathol. 5:515-525.

Green, M. R., and Sambrook, J. 2012. Molecular Cloning: A Laboratory Manual, 4th Ed. Cold Spring Harbor Laboratory, Cold Spring Harbor, New York.

Hou, Z., Xue, C., Peng, Y., Katan, T., Kistler, H. C., and Xu, J. R. 2002. A mitogen- activated protein kinase gene (MGV1) in Fusarium graminearum is required for female fertility, heterokaryon formation, and plant infection. Mol. Plant-Microbe Interact. 15:1119-1127.

Jonkers, W., Dong, Y., Broz, K., and Kistler, H. C. 2012. The Wor1-like protein Fgp1 regulates pathogenicity, toxin synthesis and reproduction in the phytopathogenic fungus Fusarium graminearum. PLoS Pathog 8:e1002724.

Karkehabadi, S., Hansson, H., Kim, S., Piens, K., Mitchinson, C., and Sandgren, M. 2008. The first structure of a glycoside hydrolase family 61 member, Cel61B from Hypocrea jecorina, at 1.6 A resolution. J. Mol. Biol. 383:144-154.

Klimes, A., and Dobinson, K. F. 2006. A hydrophobin gene, VDH1, is involved in microsclerotial development and spore viability in the plant pathogen Verticillium dahliae. Fungal Genet. Biol. 43:283-294.

Krijger, J. J., Thon, M. R., Deising, H. B., and Wirsel, S. G. 2014. Compositions of fungal secretomes indicate a greater impact of phylogenetic history than lifestyle adaptation. BMC Genomics 15:722.

Kulkarni, R. D., Kelkar, H. S., and Dean, R. A. 2003. An eight-cysteinecontaining CFEM domain unique to a group of fungal membrane proteins. Trends Biochem. Sci. 28:118-121.

Leach, J., Lang, B. R., and Yoder, O. C. 1982. Methods for selection of mutants and in vitro culture of Cochliobolus heterostrophus. Microbiology 128:1719-1729.

Lievens, B., Houterman, P. M., and Rep, M. 2009. Effector gene screening allows unambiguous identification of Fusarium oxysporum f. sp. lycopersici races and discrimination from other formae speciales. FEMS Microbiol. Lett. 300:201-215.

Lodish, H. L., Berk, A., Zipursky, S. L., Matsudaira, P., Baltimore, D., and Darnell, J. 2000. Molecular Cell Biology, 4th Ed. W. H. Freeman and Company, New York.

Lu, S., Faris, J. D., Sherwood, R., Friesen, T. L., and Edwards, M. C. 2014. A dimeric PR-1-type pathogenesis-related protein interacts with ToxA and potentially mediates ToxA-induced necrosis in sensitive wheat. Mol. Plant Pathol. 15:650-663.

Lu, S., Friesen, T. L., and Faris, J. D. 2011. Molecular characterization and genomic mapping of the pathogenesis-related protein 1 (PR-1) gene family in hexaploid wheat (Triticum aestivum L.). Mol. Genet. Genomics 285: 485-503.

Lu, S., Turgeon, B. G., and Edwards, M. C. 2015. A ToxA-like protein from Cochliobolus heterostrophus induces light-dependent leaf necrosis and acts as a virulence factor with host selectivity on maize. Fungal Genet. Biol. 81: 12-24.

Lu, S.-W., Kroken, S., Lee, B. N., Robbertse, B., Churchill, A. C., Yoder, O. C., and Turgeon, B. G. 2003. A novel class of gene controlling virulence in plant pathogenic ascomycete fungi. Proc. Natl. Acad. Sci. USA 100: 5980-5985.

Lysoe, E., Seong, K. Y., and Kistler, H. C. 2011. The transcriptome of Fusarium graminearum during the infection of wheat. Mol. Plant-Microbe Interact. 24:995-1000.

Marchler-Bauer, A., Derbyshire, M. K., Gonzales, N. R., Lu, S., Chitsaz, F., Geer, L. Y., Geer, R. C., He, J., Gwadz, M., Hurwitz, D. I., Lanczycki, C. J., Lu, F., Marchler, G. H., Song, J. S., Thanki, N., Wang, Z., Yamashita, R. A., Zhang, D., Zheng, C., and Bryant, S. H. 2015. CDD: NCBI's conserved domain database. Nucleic Acids Res. 43:D222-226.

Oliver, R. P., Friesen, T. L., Faris, J. D., and Solomon, P. S. 2012. Stagonospora nodorum: From pathology to genomics and host resistance. Annu. Rev. Phytopathol. 50:23-43.

Paper, J. M., Scott-Craig, J. S., Adhikari, N. D., Cuomo, C. A., and Walton, J. D. 2007. Comparative proteomics of extracellular proteins in vitro and in planta from the pathogenic fungus Fusarium graminearum. Proteomics 7: 3171-3183.

Park, C. M., Bruenn, J. A., Ganesa, C., Flurkey, W. F., Bozarth, R. F., and Koltin, Y. 1994. Structure and heterologous expression of the Ustilago maydis viral toxin KP4. Mol. Microbiol. 11:155-164.

Pazzagli, L., Cappugi, G., Manao, G., Camici, G., Santini, A., and Scala, A. 1999. Purification, characterization, and amino acid sequence of ceratoplatanin, a new phytotoxic protein from Ceratocystis fimbriata f. sp. platani. J. Biol. Chem. 274:24959-24964.

Prados-Rosales, R. C., Roldan-Rodriguez, R., Serena, C., Lopez-Berges, M. S., Guarro, J., Martinez-del-Pozo, A., and Di Pietro, A. 2012. A PR-1-like protein of Fusarium oxysporum functions in virulence on mammalian hosts. J. Biol. Chem. 287:21970-21979.

Proctor, R. H., Hohn, T. M., and McCormick, S. P. 1995. Reduced virulence of Gibberella zeae caused by disruption of a trichothecene toxin biosynthetic gene. Mol. Plant-Microbe Interact. 8:593-601. 
Rep, M. 2005. Small proteins of plant-pathogenic fungi secreted during host colonization. FEMS Microbiol. Lett. 253:19-27.

Rosenkrands, I., and Andersen, P. 2001. Preparation of culture filtrate proteins from Mycobacterium tuberculosis. Methods Mol. Med. 54:205-215.

Seong, K., Hou, Z., Tracy, M., Kistler, H. C., and Xu, J. R. 2005. Random insertional mutagenesis identifies genes associated with virulence in the wheat scab fungus Fusarium graminearum. Phytopathology 95:744-750.

Sperschneider, J., Gardiner, D. M., Thatcher, L. F., Lyons, R., Singh, K. B., Manners, J. M., and Taylor, J. M. 2015. Genome-wide analysis in three Fusarium pathogens identifies rapidly evolving chromosomes and genes associated with pathogenicity. Genome Biol. Evol. 7:1613-1627.

Stergiopoulos, I., and de Wit, P. J. G. M. 2009. Fungal effector proteins. Annu. Rev. Phytopathol. 47:223-263.

Stergiopoulos, I., van den Burg, H. A., Okmen, B., Beenen, H. G., van Liere, S., Kema, G. H., and de Wit, P. J. 2010. Tomato $C f$ resistance proteins mediate recognition of cognate homologous effectors from fungi pathogenic on dicots and monocots. Proc. Natl. Acad. Sci. USA 107:7610-7615.

Szyperski, T., Fernandez, C., Mumenthaler, C., and Wuthrich, K. 1998. Structure comparison of human glioma pathogenesis-related protein GliPR and the plant pathogenesis-related protein P14a indicates a functional link between the human immune system and a plant defense system. Proc. Natl. Acad. Sci. USA 95:2262-2266.

Talbot, N. J., Ebbole, D. J., and Hamer, J. E. 1993. Identification and characterization of $M P G 1$, a gene involved in pathogenicity from the rice blast fungus Magnaporthe grisea. Plant Cell 5:1575-1590.
Templeton, M. D., Rikkerink, E. H. A., and Beever, R. E. 1994. Small, cysteine-rich proteins and recognition in fungal-plant interactions. Mol. Plant-Micorbe Interact. 7:320-325.

Tzeng, T. H., Lyngholm, L. K., Ford, C. F., and Bronson, C. R. 1992. A restriction fragment length polymorphism map and electrophoretic karyotype of the fungal maize pathogen Cochliobolus heterostrophus. Genetics 130:81-96.

Urban, M., King, R., Hassani-Pak, K., and Hammond-Kosack, K. E. 2015. Whole-genome analysis of Fusarium graminearum insertional mutants identifies virulence associated genes and unmasks untagged chromosomal deletions. BMC Genomics 16:261.

Van den Ackerveken, G. F., Van Kan, J. A., Joosten, M. H., Muisers, J. M., Verbakel, H. M., and De Wit, P. J. 1993. Characterization of two putative pathogenicity genes of the fungal tomato pathogen Cladosporium fulvum. Mol. Plant-Microbe Interact. 6:210-215.

Van Loon, L. C., and Van Strien, E. A. 1999. The families of pathogenesisrelated proteins, their activities, and comparative analysis of PR-1 type proteins. Physiol. Mol. Plant Pathol. 55:85-97.

Voigt, C. A., Schafer, W., and Salomon, S. 2005. A secreted lipase of Fusarium graminearum is a virulence factor required for infection of cereals. Plant J. 42:364-375.

Walter, S., Nicholson, P., and Doohan, F. M. 2010. Action and reaction of host and pathogen during Fusarium head blight disease. New Phytol. 185:54-66.

$\mathrm{Xu}, \mathrm{X}$., and Nicholson, P. 2009. Community ecology of fungal pathogens causing wheat head blight. Annu. Rev. Phytopathol. 47:83-103. 